\title{
From Cooking to Commoning: The Making of Intangible Cultural Heritage in OneLoveKitchen, Athens
}

\author{
Penny Travlou
}

This chapter is a critical discussion of intangible cultural heritage (ICH) and its conceptual predicates through the lens of a self-organised, collective, culinary project: OneLoveKitchen, an African collective kitchen in Athens, founded and sustained by a group of undocumented migrants and refugees from Africa along with local and international activists. It examines the emergence of a very distinctive kind of translocal cultural heritage through the sharing of cooking practices, skills and knowledge, and discusses how sharing was conflated with the crossing and contesting of borders. OneLoveKitchen demonstrates how cultural values can be co-created by agents of diverse national, socio-cultural, economic, political and religious backgrounds, who have embarked upon a common project motivated by a desire to care for each other in a safe, communal space shared and owned by all. The obvious challenge here is how to re-define ICH by taking into account transcultural, transnational and nomadic contexts of cultural production. What are the cultural values shared within a newly constituted community of former strangers with different personal histories, geographies and everyday experiences? How can these differences be negotiated to create and enrich - a shared common space of care and active citizenship?

How to cite this book chapter:

Travlou, P. 2020. From Cooking to Commoning: The Making of Intangible Cultural Heritage in OneLoveKitchen, Athens. In Lekakis, S. (ed.) Cultural Heritage in the Realm of the Commons: Conversations on the Case of Greece. Pp. 159-182. London: Ubiquity Press. DOI: https://doi.org/10.5334/bcj.j. License: CC-BY 


\section{Culinary Practices as Intangible Cultural Heritage (ICH)}

In recent years, the discussion on cultural heritage has moved beyond its earlier (and arguably limited) focus on tangible objects such as artefacts, monuments, architectural and archaeological sites of historical significance. The concept of cultural heritage has been broadened to encompass a greater diversity of cultural manifestations, including intangible cultural practices such as:

"customs and oral traditions, music, languages, poetry, dance, festivities, religious ceremonies [...] systems of healing, traditional knowledge systems and skills connected with the material aspects of culture, such as tools and the habitat" (Bouchenaki 2003: 1).

International organisations such as UNESCO and ICOMOS, the International Council on Monuments and Sites, have acknowledged that tangible and intangible cultural heritage (ICH) are bound inextricably (ICOMOS 2002). However, it has taken a very long time - particularly for UNESCO - to recognise intangible cultural heritage as equally important to tangible artefacts, monuments and sites. This came after much criticism by indigenous groups against the hierarchical, colonial and "unconditionally" elitist approach to cultural heritage by UNESCO (Brulotte \& Di Giovine 2016: 12). As a response to this rightful criticism, UNESCO set up the Representative List of the Intangible Cultural Heritage of Humanity which follows the same structure with the World Heritage List, "yet purports to be more democratizing and even less determinate in its standards of selection" (Brulotte \& Di Giovine 2016: 12). In this Intangible Cultural Heritage List, there is recognition of equal importance of people's everyday cultural practices, knowledge and skills to that of artefacts and monuments.

Specifically, UNESCO has proposed a set of criteria that would render a cultural practice recognised as Intangible Cultural Heritage. According to these criteria, such a cultural practice must be, a) traditional, and 'living' at the same time; b) inclusive; c) representative; and, d) community-based (UNESCO 2011). For UNESCO, ICH can represent traditions of the past as much as of the present; ICH practices can be deployed in rural and/or urban areas, by diverse groups, including groups that have migrated from one place to another. ICH contributes "to social cohesion, encouraging a sense of identity and responsibility which helps individuals to feel part" of a community (UNESCO 2011). $\mathrm{ICH}$ is, therefore, a cultural good that is passed from generation to generation and is shared between members of a community as well as with other communities. Most importantly, however, ICH can only be recognised as such by the communities wherein it is produced, maintained and transmitted. Along these lines, traditional culinary practices have recently been recognised as $\mathrm{ICH}$, since these practices encompass voices, values, traditions, skills, knowledge, 
craftmanship, technologies, tools, storytelling and oral history (see ICH: ICH-UNESCO 2017).

In the introduction of their book "Edible Identities: Food as Cultural Heritage", Michael Di Giovine and Ronda Brulotte share their observation that:

"[A]most immediately after the ratification of the Intangible Heritage Convention, nation-states in Latin America and Western Europe, for whom food already factore into heritage claims and touristic imaginaries, began drawing up inventories cataloguing, and thereby constructing, a systematic narrative about their cuisines" (Brulotte \& Di Giovine 2016: 13).

In the $12^{\text {th }}$ session of the Intergovernmental Committee for the Safeguarding of the ICH (Republic of Korea, December 2017), a culinary practice, the making of the Neapolitan pizza, was recognised as $\mathrm{ICH}$ for the first time; as such it became included in the Representative List of the ICH of Humanity. The Committee described the art of the Neapolitan 'pizzaiuolo' (pizza maker) as,

"a culinary practice comprising four different phases relating to the preparation of the dough and its baking in a wood-fired oven, involving a rotatory movement by the baker. The element originates in Naples, the capital of the Campania Region, where about 3,000 Pizzaiuoli now live and perform. Pizzaiuoliare alivinglinkfor the communities concerned. [...] The element fosters social gatherings and intergenerational exchange, and assumes a character of the spectacular, with the Pizzaiuolo at the centre of their 'bottega' sharing their art. However, knowledge and skills are primarily transmitted in the 'bottega', where young apprentices observe masters at work, learning all the key phases and elements of the craft" (ICH-UNESCO, 2017).

Notable in this description is the emphasis on the contribution of the pizzaiuolo's art on sociability, knowledge exchange and the maintenance of community links. Evidently, these criteria weighted heavily in the recognition of the pizzaiuolo's art as ICH. It is, thus, the potential of this culinary practice to bring people together and to enable them to share the knowledge of pizza recipes that is considered to hold cultural value. The official recognition of the Neapolitan pizzaiuolo's art as ICH exemplifies this understanding of cultural value and invites an enquiry on 'food' as a social practice that holds cultural value. Beyond this, it looks at the way food and culinary practices bond people together and build new and/or strengthen existing communities through sharing cooking practices, skills and traditional knowledge. The art of the Neapolitan pizzaiuolo has also crossed borders creating a strong transglobal network of pizza makers whose skills and knowledge have bonded together the Italian diaspora and connected with other local and translocal communities to redefine ICH in a mobile transcultural context. 


\section{Being Collaborative - Being Ethnographic}

Building upon previous ethnographic work on collaborative and peer learning practices within emerging networks of digital art practitioners (Travlou 2013), while on sabbatical in Athens in 2015, I embarked on a project looking at the influx of newcomers to the city- mainly artists and activists from the Global North and immigrants and refugees from Africa and the Middle East. The arrival of refugees in Greece peaked in the summer of that year, with hundreds of people arriving daily after a perilous Aegean crossing. I was interested in exploring the solidarity networks emerging within Athens to support migrants and refugees. At the same time, I became involved with several initiatives within this solidarity network as an active participant. OneLoveKitchen, the African collective kitchen that forms the focus of this chapter, was one such initiative in which I participated from the outset. A brief comment on my multi-fold role as a researcher, activist and member of the kitchen is warranted here; this can also serve as a short testimony on the collaborative methodology I used in the course of the project.

Reflecting the current shift of ethnographic research towards the investigation of nomadic and multi-sited communities (Marcus 1998), this ethnography of OneLoveKitchen looked at a mobile group. Local and international activists and migrants/refugees had been in constant movement across international borders and the urban space(s) of Athens; many refuges/migrants hoped to continue their journey further, to Germany or other countries in Northern Europe. The ethnographic methodology was shaped by - and mirrored - the networks, spaces, practices of co-creation and the collaborative ethos of this 'subject' community, which, for my sojourn in Athens also became my community.

This was a collaborative ethnography (Lassiter 2005). Collaboration was employed as a tool to contest knowledge hierarchies: it enabled horizontal practices of doing fieldwork together, with everyone else involved in the kitchen. Kitchen members were active participants in the fieldwork process, while I participated in all the tasks and practices that sustained the kitchen.

Creativity is understood as emerging from the synergy of spaces, practices and artefacts, interlinked so that they constitute an assemblage (Deleuze \& Guattari 1987). Spaces are inhabited by bodies; practices are performed by bodies; artefacts are made by (and in some sense are themselves) bodies. The underpinning commonality here is, therefore, a network of interacting bodies linked by actions, biographies, stories. In OneLoveKitchen, collective making and sharing takes place at the intersection, and through the weaving together, of multiple storylines. This topology of distributed agency and interconnection resembles that of a mesh network: a rhizome. Ethnographic fieldwork in OneLoveKitchen thus became a quest for interactions between places, people and things. My attempt to follow the storylines embodied in the making of the kitchen led me to a "rhizomic ethnography" (Leach 2003; Travlou 2013). This rhizomic 
topology also permitted me to explore various entry points to OneLoveKitchen, both during fieldwork and while writing the ethnographic text. To do justice to the rhizomic, multivocal and horizontal nature of the kitchen (and fieldwork), this chapter eschews a linear narrative structure.

\section{Nomadic subjectivities, active citizenship and intangible culture}

OneLoveKitchen was founded in 2015, in what was, for Athens (and Greece as a whole), a socio-political turning point: a moment of accelerated economic, social and demographic change, often referred to, in both the media and everyday conversation, as 'I Krisi, the Crisis (see Mitsopoulos \& Pelagidis 2011; Douzinas 2013; Pleios 2013; Mylonas 2014; Tsilimpounidi 2016). This crisis is usually portrayed as an impeding, even accomplished catastrophe. Yet, amidst the very real pressures generated by massive state debt, neoliberal austerity, extensive impoverishment and large numbers of newcomers in need (refugees, other migrants), there are also processes and agents that make possible the emergence of innovative models of living, sharing of resources, surviving and resisting oppressive state policies. Departing from current mainstream representations of the 'crisis' ('financial'/'debt crisis'; 'refugee crisis') as (only) a catastrophe, I wanted to explore opportunities for socio-political change and novel forms of participatory citizenship that could emerge from the collaboration, friendship, care, trust - in one word, comradeship - between people that this 'crisis' brought together. OneLoveKitchen offered me an appropriate - and very welcoming - place in which to attempt this exploration.

I also wanted to move beyond the stereotypical representation of migrants/ refugees as outlined in Giorgio Agamben's Homo Sacer (Agamben 1998) people with fewer rights than the citizens of nation-states - and explore their nomadic experiences and practices of active political engagement as possible catalysts of social and cultural change in the host-society. This theoretical shift challenges the tendency to view refugees/migrants as (merely) economic, rather than socio-political actors - a tendency that often obscures the numerous ways in which refugees/migrants exercise political agency. Many practices of refugees and migrants are, indeed, political acts, even though they often differ from the forms of mobilisation and protest readily recognised as 'political' in the host society.

Rosi Braidotti's (2011) notion of "nomadic subjectivity" helps us to realise how refugees/migrants - newcomers and 'strangers' who inhabit space in a non-sedentary manner, challenge the bounded territory of the nation-state. For Deleuze and Guattari (1987), nomadism designates a way of occupying space while subscribing to a kind of rule, a custom, outside that of social respect or engagement. Nomadic citizenship can be seen as a new paradigm of citizenship 
that, while contributing to the making of shared cultural values in the city, at the same time challenges and contests these values. This paradigm of citizenship is predicated upon the sense of belonging to a transnational network detached from the bounded territory of the nation-state and, therefore, potentially oppositional to the myriad exclusions and the proclivity to violence that state citizenship entails (Holland 2012). As Arjun Appadurai concludes in an essay on the future of patriotism, citizenship "become[s] plural, serial, contextual and mobile" (Appadurai 1993: 428). In this respect, nomadic citizenship entails voluntary membership of self-organising groups of various kinds and scales. Borrowing Papadopoulos and Tsianos' words, what constructs mobile citizenship is "the sharing of knowledge and infrastructures of connectivity, affective cooperation, mutual support and care among people on the move" (2013: 178). Nomadic citizenship thus tends to break the state's monopoly on controlling citizenship: it re-distributes social belonging among other groups and across other, non-state sanctioned forms of group organisation (Holland 2012). OneLoveKitchen, founded and sustained by nomads, people on the move, is a case in point.

How does nomadic citizenship relate to the intangible cultural heritage? The vital question here is one of practices and conditions of cultural production: who produces ICH in the transient, contested spaces shared and shaped by newcomers and locals alike? Where, by what means, and through what practices does this production take place?

As already mentioned, one of UNESCO's four identifying criteria of ICH is its community-based character. This criterion may be taken to imply that $\mathrm{ICH}$ can only be (re-)produced within a settled, localised community. This implication is further supported by the claim (often made by symbolic anthropologists) that a community is the result of 'boundary construction through identity and shared systems of meaning' (Cohen 1985 qtd. in Guimarães 2005: 146). The nomadic constituents of OneLoveKitchen clearly fall short of this criterion. Is this then to imply that the mingling of ingredients, recipes, food, stories and bodies in OneLoveKitchen does not qualify as intangible culture?

This impasse brings into focus the limitations of the concept of community as an identifying criterion for ICH. Community is predicated upon a disposition of boundaries - be they boundaries in space or/and boundaries in membership. As such, a community often excludes newcomers, especially those who do not share its common (foundational) histories and values. The nomadic citizenship practiced in OneLoveKitchen challenges this limiting and exclusionary understanding of the concept of community.

It seems that a more appropriate organisational concept - permissive, open, and fluid enough to accommodate nomadic lives on the move - is that of a network, a meshwork (Ingold 2010). Unlike the conception of community, based on (fixed) identity and the construction of boundaries, a meshwork is an emergent phenomenon in constant flux. It is constituted from "interwoven lines 
of growth and movement" (Ingold 2010: 4); trajectories of bodily movement across continents, oceans and time, stories of lives in motion that render multivocality explicit within an ever-changing structure of entanglement. Understood in this way, a meshwork cannot be static: it is always in-the-making, as new actors arrive and continuously reshape it. Neither can it be closed and firmly fixed in space: the ever-changing storylines that constitute it are formidably extendable.

An ever-growing number of people - migrants, refugees, 'cosmopolitans' and others - are constantly on the move. They meet and constitute meshworks of co-existence and solidarity, where they enact nomadic citizenship and, in the course of this, produce intangible culture. Our understanding of what counts as $\mathrm{ICH}$, therefore, needs to take these practices, social contexts and distributed topologies and cultural production into account.

\section{Sharing is caring: Food and politics in OneLoveKitchen}

Compared with other European capital cities, Athens is not regarded as a hub of 'ethnic' cuisines. This may be due to the dominance of the Greek culinary tradition: there may be less of a local interest in experimenting with different tastes. However, Greek cuisine itself manifests the country's geopolitical situation on the crossroad between East and West in its eclectic merging of flavours and recipes from Turkey, the Balkans, Italy and France. A number of emblematic Greek dishes (e.g. tzatziki, moussakas, imam, soutzoukakia, baklavas) come straight from the culinary tradition of the Ottoman Empire/Turkey - particularly from that of Istanbul and the urban centres of the Aegean coast where many Greeks lived before the 1923 Greece-Turkey population exchange. Dishes of these earlier Greek refugees brought new flavours to the local palette: cumin, aniseed, cloves etc. Since the 1990s, with the arrival of economic migrants of different nationalities in Athens, there has been an expansion in restaurants dedicated to 'ethnic' cuisines. Migrants from China, Pakistan, India, Ethiopia, Kurdistan and Iraq have established restaurants in and around the city centre, mostly catering for a migrant clientele. These restaurants are usually in neighbourhoods with populous migrant communities. A smaller number of more 'upmarket' 'ethnic' restaurants cater for a mixed clientele of Greeks, migrants and tourists.

As African cooks informed me, alongside these licensed restaurants there is also a network of homemade food catering businesses that serve migrant communities. These businesses are part of an informal economy where non-monetary exchanges of services are often permissible (e.g. someone can provide home-cooked lunches in exchange of a haircut or child minding). Our Eritrean cook in OneLoveKithen, for instance, would often bake bread in her basement flat in exchange for haircuts. This informal economy can be viewed as 
a form of collaborative economy where "assets or services are shared between private individuals, either for free or for a fee” (Gañigueral 2015).

As mentioned earlier, the African collective kitchen consisted of undocumented (sans papiers) African migrants and refugees along with local and international Greek activists. We were from Senegal, Gambia, Nigeria, Ethiopia, Eritrea, UK, Hungary, Italy, the USA and Greece, of different age, gender, sexuality, race, religion, education, employment and economic status. Languages within the group varied too: we spoke English, Greek, French, Wolof and Amharic. When necessary, we would interpret between these languages. Some of us were professional chefs; others had just started learning how to cook; a few others were responsible for organising and promoting our events. Each member of the collective had one or more distinct roles, according to individual skills and interests (Social Innovation Europe 2016).

Our aim was to create a safe, shared, social space where we would care for each other, cook together, share food and organise pop-up events across the city where people could come together to taste well cooked and novel dishes and to meet one another. We hoped that this interaction could facilitate cultural exchange and social transformation. Equally important to us was our desire to challenge hegemonic notions of exchange value and the idea that value is produced only through "action that is considered labour" (see Wilson 2017: 132). We wanted to show that, independent of their potential to produce goods and services for exchange, actions of solidarity constitute value-in-themselves. We saw value as determined by the potential of people's actions to translate into, inform and enrich meaning; to be "meaningful [and, in our project, explicitly political] action" (Taylor 2017: 191 in Wilson 2017: 132).

We applied a model of solidarity economy, based on practices of participatory budgeting, heterarchy, horizontal decision-making, collective self-organisation and peer learning. Many of our African members brought their experiences of informal economy to the project. These experiences were cross-pollinated with experiences of collaborative economy that other members had practiced. Our principles and operational practices were explored, discussed and reinforced in regular (weekly) assemblies.

For five months, OneLoveKitchen organised regular pop-up events in various locations across Athens: from the rooftop of Nosotros, a free social space in Exarchia, at the very centre of Athens (Figure 1), to an anti-racist festival in the occupied space of Votanicos Park, a former botanic garden, and academic conferences in two squatted art spaces: EMBROS theatre and café-bar Green Park (Figure 2). The collective kitchen was self-funded through fees charged for catering services and individual donations. Due to the self-organised and non-legal status of the kitchen, we were not able to invoice for our catering services. We kept our prices low to make our food accessible to people who, in the midst of the financial crisis would have found it difficult to spend much on eating out (Figure 3). We never managed to make much profit, but what we 


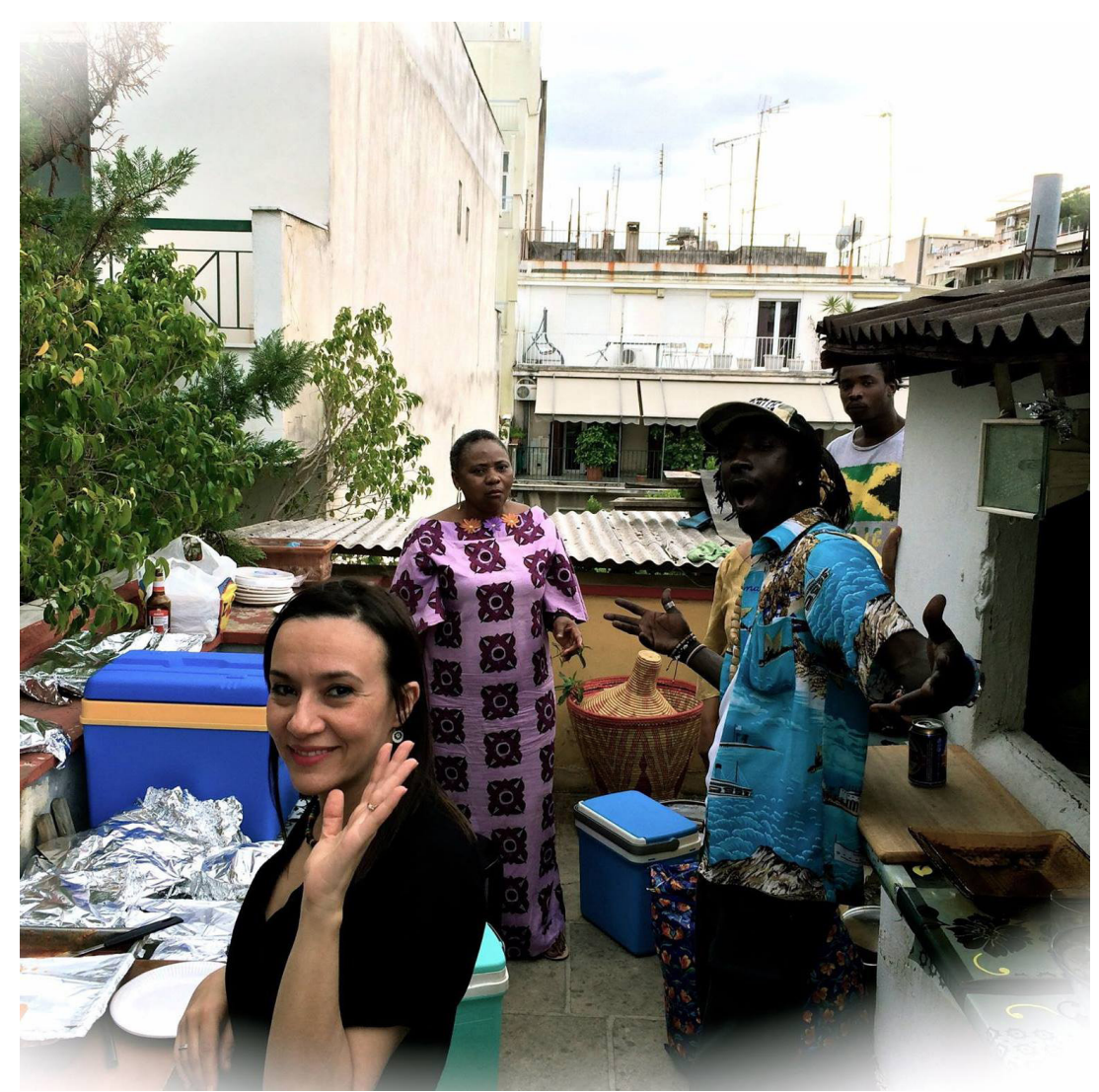

Figure 1: Pop-up event in Nosotros (Source: author).

earned from each event was shared equally among all of us regardless of our individual financial situation. We thought that unequal distribution of earnings would have disempowered some members by placing them in the position of recipients of charity. Those of us who were in less precarious financial position and had a steady income, however, used our share of the earnings to purchase cooking equipment and to cover other expenses incurred from our catering events (e.g. hire and repair of a van). We also followed a participatory budgeting framework to collectively decide how and where to spend our budget. In this, we were inspired by citizen and neighbourhood assemblies in Latin American cities, which use participatory budgeting as a tool for economic democracy, to involve those (e.g. low-income residents, non-citizens, the youth) left out by conventional methods of public engagement (Participatory Budgeting Project 2012). In our case, this was particularly relevant for migrant and refugee 


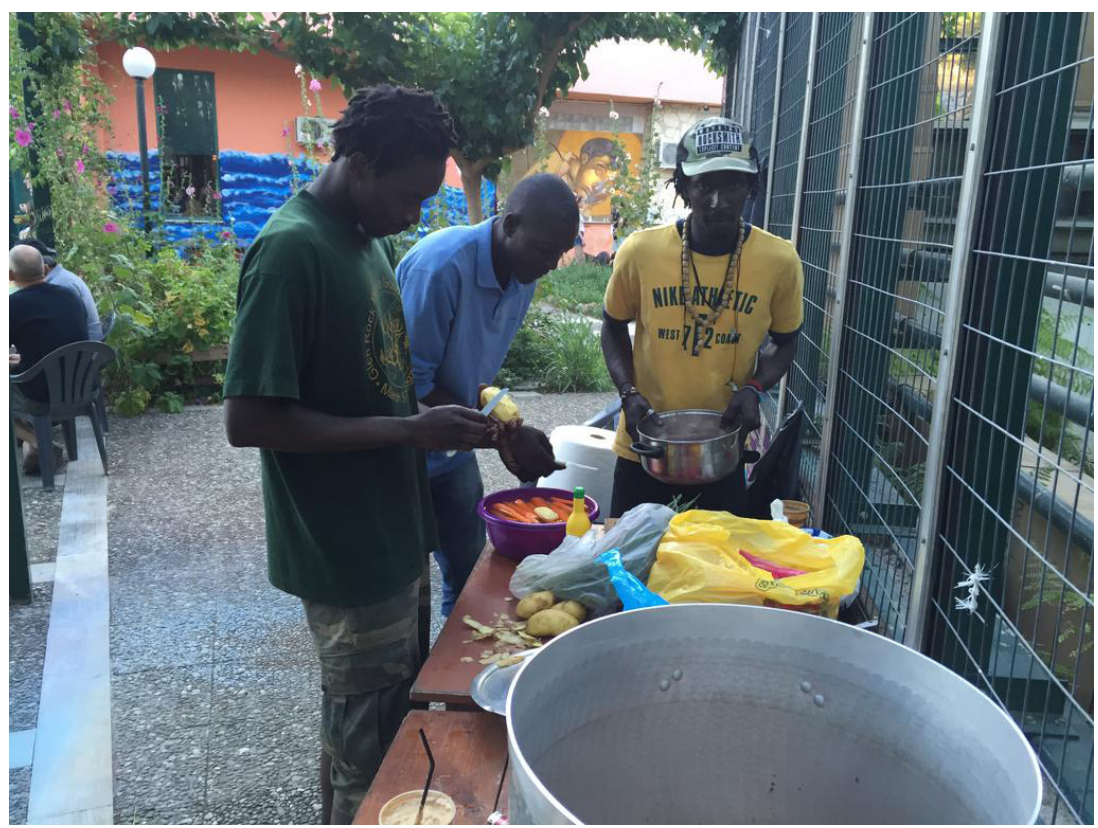

Figure 2: Senegambian cooks in occupied Votanikos Park (Source: author).

members (sans papiers) who, by lacking a residence and work permit, had no legally sanctioned access to employment.

Our decision-making practices aimed explicitly at challenging power structures. All decisions pertaining to the functioning of OneLoveKitchen were made collectively in weekly assemblies (Travlou 2017; see Figure 4). Some members already had considerable experience of participating in assemblies; others did not. Speaking in front of the whole group was not easy for some, particularly at the beginning, when most of us were just beginning to get to know each other. To enable communication and allow all members to find a voice, one of us facilitated the assembly, using the Art of Hosting, "a suite of powerful conversation processes to invite people to step in and take charge of the challenges facing them" (Art of Hosting n.d.). Our assemblies started in a circle: the 'host' addressed a generic question to the group and each member responded in their turn. On one such occasion, in the early days of the project, the host asked us: "are you in love today?" To our surprise, all of us responded, and by the end of the assembly that morning some remarked that they felt a stronger bond with the rest of the group. This is how we came up with a name for our project: OneLoveKitchen.

The assembly was not only a platform for discussion of operational matters, but also for the exchange and sharing of personal stories, struggles and reflections on everyday life in Athens. In the assemblies, particularly in those facilitated through the Art of Hosting, it became evident that we cared for 


\section{MENU}

meat:

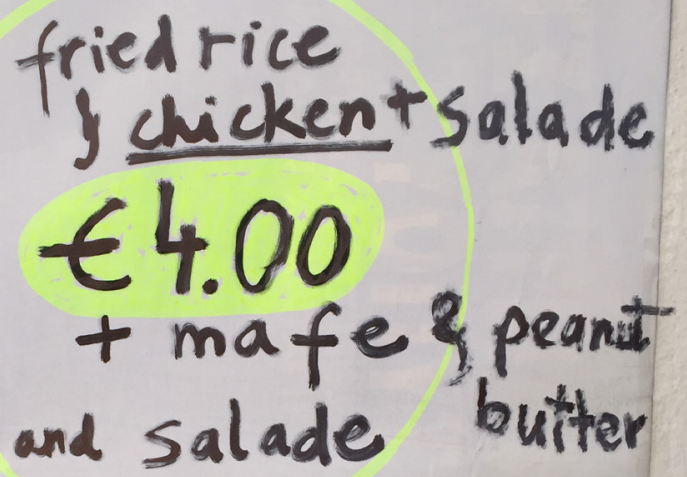

\section{Veggie:}

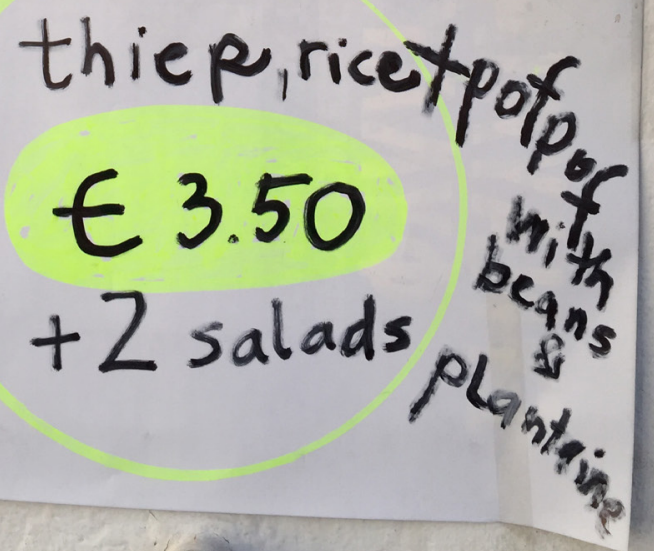

Figure 3: OneLoveKitchen Senegalese Menu (Source: author).

each other and that we were all determined to ensure that each of us was healthy and content.

A further, equally crucial function of the weekly assemblies was the building and maintenance of trust between members. This was not always easy: conflict was unavoidable on several occasions, and this became apparent in the assemblies. In a group of people as diverse as ours, from so many different cultures, political ideologies and religious beliefs, conflict was expected - even valued, as it helped 


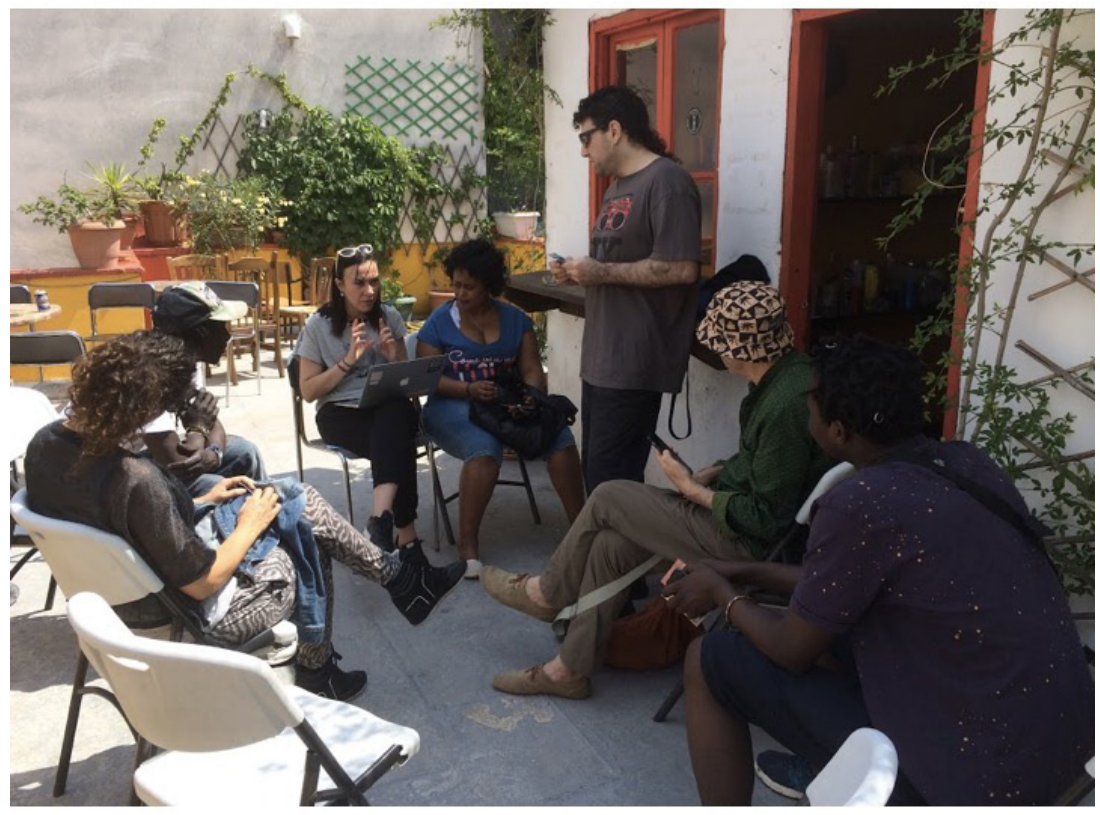

Figure 4: OneLoveKitchen Assembly (Source: author).

us to better understand our differences and positionalities. Conflict was dealt with in the assemblies, with mediators - other members - stepping in to resolve issues through encouraging dialogue between those in dispute. Conflict can also be regarded as a driver for both individual and collective change, particularly as it challenges the knowledge, skills, experiences and expectations that each member brings into the community. Overcoming conflict was about, firstly, recognising difference, and then allowing individual members to unlearn; to shift their knowledge paradigm and accept to learn afresh. As Carmen Elena Cirnu argues "[T]he concept of unlearning is intrinsically bound to the concept of change" (2015: 131). In our African collective kitchen, our conflict resolution practices involved unlearning. This is something we arrived at spontaneously. Some of us learned to be more accepting of racial, gender and religious differences; others learned to share more openly our stories; while others learned to do things with others and to value collective interest more than individual gain.

What enabled us to sustain our project through these episodes of conflict was our trust on our common values of equality and sharing. These common values were constantly reinforced in the assemblies. It became evident that, beyond our differences, we all desired to care for each other, share knowledge and skills and act in solidarity whenever the need arose. By solidarity, here, I mean both the principle that can inspire and guide action in support of one another (Arendt 1990: 88-89) and the relationships built upon this principle (Vasiljevic 2016: 381). 
Cooking is often regarded as a gendered, feminine activity, a characteristic of the domestic, a private sphere related to social reproduction.

"[F]ood work has typically been relegated to women or otherwise marginalized peoples and excluded from the purportedly more sophisticated, abstract activities of knowledge production" (Brady 2011: 322).

This confinement in the domain of 'home economics' - women's unpaid labour, as part of their house chores - disassociates cooking from political action. Yet, it is its very nature as an act of care for the other members of the household/collective that makes cooking a political praxis (see Arendt 1958). Care encompasses:

"being mindful, looking after, attending the needs, and being considerate, [...] both awareness of dependency, possession of needs, and relatedness as basic elements of the human constitution and also concrete caring activities in a broad sense. It involves "caring for the world", not only by means of nursing and social-work activities or housework in the narrow sense, but also by dedication to a cultural transformation" (Knecht et al. 2012: 37).

In OneLoveKitchen, care played a central role in bringing us together and transforming our lives in various ways. Some of us lived precarious, 'bare lives' (to use Agamben's term), without legal status, housing and steady employment, and confronted with harsh and challenging daily experiences. The kitchen was a caring and safe shared space sustained through its members' actions of solidarity. When our Eritrean cook was threatened by her landlord with eviction, another member from Sierra Leone reassured her: "you are not alone, we are together. And together, we are power". Members of OneLoveKitchen, came together to organize legal support. Her eviction was overturned and she managed to remain in her rented flat.

Care work - the material and affective labour of seeing to another person's needs - was also a paid professional activity for many OneLoveKitchen members. Most of the African women participating in the kitchen also worked, for very low wages, as home carers and cleaners in residential care homes for the elderly, hospitals, bars and restaurants. The intersectional oppression that these women experienced as racialised, gendered and underclass subjects in Greece has motivated them to self-organise and set up the United African Women Organisation which lobbies for equal rights for migrant women and their children in Greece. Their first-hand experiences of exploitation and marginalisation, where their affective labour, although monetised as 'paid labour', remained underpaid and devalued, led them to deploy 'care' as political action. In this way, they became political subjects demanding visibility and justice. This "politics of care" encouraged African migrant women care-workers to develop a political consciousness in which caring is invoked as the power to build new 

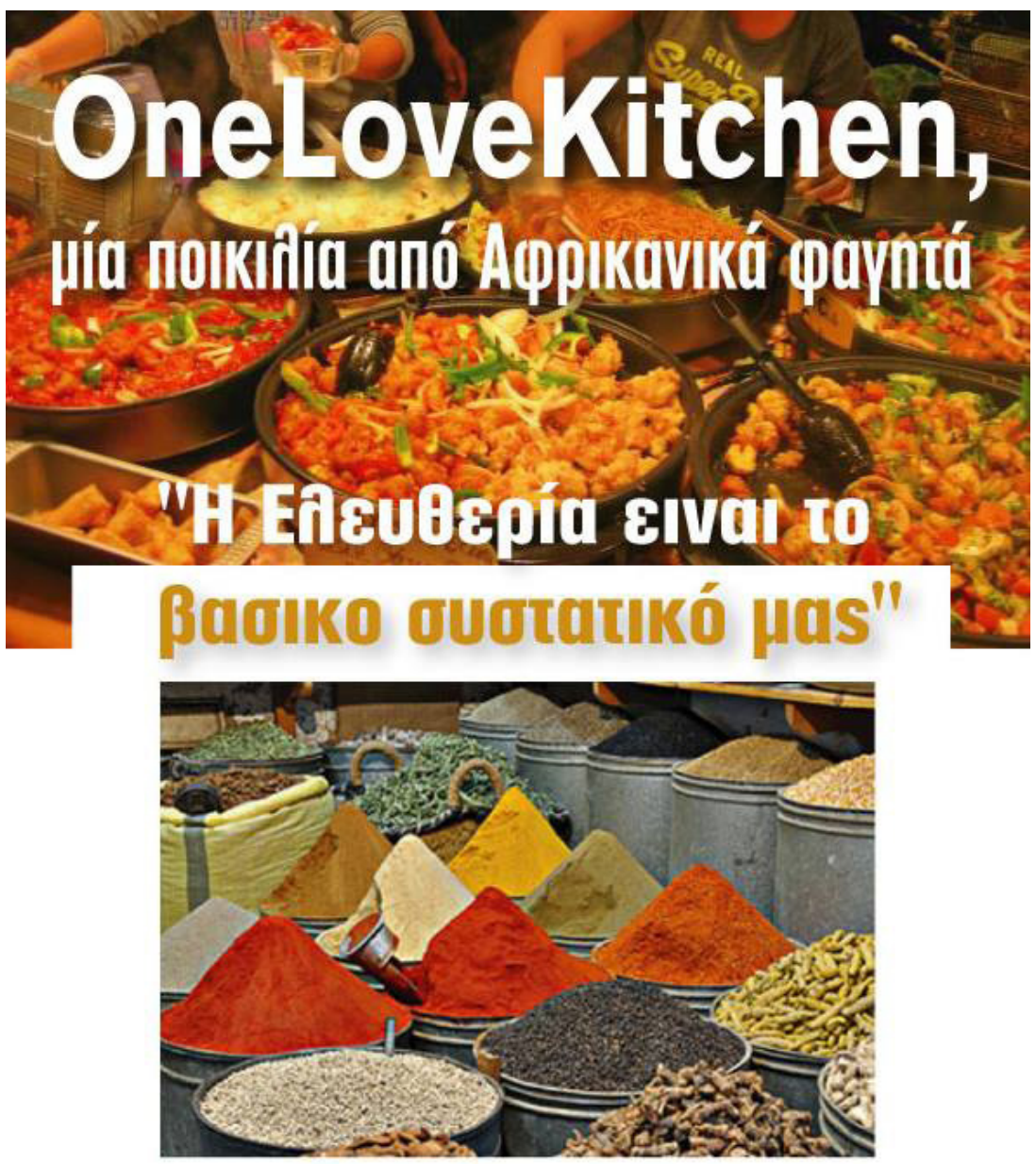

\section{Kupıakń 14 louvíou 18:00 „цéxpı apүá}

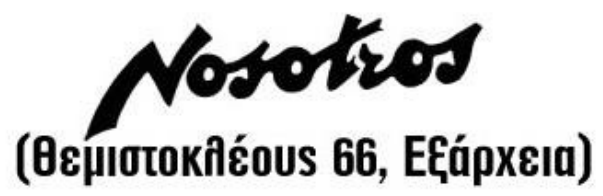

Figure 5: OneLoveKitchen event poster (Source: Nosotros \& author).

kinds of active citizenship and solidarity (see also Hill Collins 2000; Bassel \& Emejulu 2018).

These African migrant women brought their distinctive political subjectivity and their know-how of grassroots activism and politics of care to OneLoveKitchen. Most importantly, they decolonised political action and made 
their means and methods of struggle relevant and instructive to local and foreign activists in our group. We should note that sharing and caring are concepts deeply rooted in African traditions of political struggle: 'Ubuntu', originally a Zulu concept, is widely used across Africa to describe a universal bond of sharing that connects all humanity: the notion that "a person is a person through other persons" (Shutte 1993: 46). The concept of 'Ujamaa', a Kiswahili term translated as 'familyhood' or 'brotherhood' (Cornelli 2012), central to Julius Nyerere's formulation of African Socialism (Nyerere 1968), is another case in point. For Nyerere, Ujamaa is "an attitude of mind [...] needed to ensure that the people care for each other's welfare"; this is a precondition for a just society (1977: 1).

Caring was thus valued as an empowering political act from the very beginning of OneLoveKitchen. Since our cooking took place not in a domestic or commercial setting but out in the public sphere (the polis), we saw the opportunity to develop the kitchen as a political space for empowerment and emancipation rather than (just) a space to perfect recipes and experiment with ingredients. Our common belief that "sharing is caring", our intention to act as recipients and providers of care and solidarity and to contest the multiple facets of the crisis that Athens experienced, formed the very core of our kitchen politics. The poster publicising our very first pop-up event, on the rooftop of Nosotros in Exarchia, declared that "freedom is our basic ingredient" (see Figure 5). From the outset, we wanted to make it explicit that OneLoveKitchen was a platform for active citizenship, a political praxis.

\section{Breaking bread together: Com panis -> Companion $->$ Comrade}

As OneLoveKitchen members and political actors, we became companions and comrades. A companion (from Latin 'com panis') is a person you share bread with, you "break bread together". The Greek cognate is ' $\sigma u ́ v \tau \rho о \varphi о \varsigma^{\prime}$ (syntrofos): one you share food (' $\tau \rho \varphi \varphi$ ') with. With a comrade (from Latin 'camera': chamber) you share intimate living space. As all these cognates demonstrate, relationships of political solidarity are reinforced by acts of sharing and intimacy.

Food making and sharing is a social act of hospitality ('filoxenia' in Greek; 'teranga' in Wolof - both meaning the gift of unconditional generosity to a stranger) and connection: a means for celebrating and constantly reinforcing relationships of reciprocity. By bringing people together, a shared meal facilitates "the togetherness of the social actors" (Adapon 2008: 37). In Georg Simmel's terms, a meal mediates socialisation (1994: 350). This companionship through the sharing of food can even be achieved with very little resort to conversation. In this sense, we can think of food as an object of exchange, a gift (in Marcel Mauss' terms) that can be shared and exchanged (Mauss 1990). In her ethnographic monograph, "Culinary Art and Anthropology", Joy Adapon (2008) suggests that, 
"Food sharing is dynamic and self-extending whereas eating is socially static and self-collapsing. So, cooking is an inherently social act, and so, conversely, eating what one cooks oneself is antisocial, unless one is sharing the food" (2008: 41).

In OneLoveKitchen, we ate together regularly, in a conscious act of group bonding. This fitted in well with the culinary practices many of us had grown up with. In both Senegambian and Eritrean/Ethiopian traditions, you commonly eat with others, sharing food from the same plate. In Senegal, 'thieboudienne, a rice and fish dish, is served in a large round tray from which everyone partakes. Likewise, in Eritrea and Ethiopia, people share food served on injera, a type of flatbread. In the Greek tradition, 'mezedes' are served in small plates to be shared among all those sitting around the table.

Eating together was of great importance to us all, as we had previously been strangers, with different personal histories, geographies and points of departure. In his eponymous text, Georg Simmel defines the stranger as "somebody who comes today and stays tomorrow" (unlike the wanderer, "who comes today and goes tomorrow", Wolff 1950: 402). The stranger is,

"[a] fundamentally mobile person; [s/he] comes in contact, at one time or another, with every individual, but is not organically connected, through established ties of kinship, locality, and occupation, with any single one" (Wolff 1950: 403).

By this definition, we were all strangers: the kitchen was where we all came together, to work on a project that we collectively owned. It was our cooking and eating together that shaped our project as a common shared space of care and solidarity wherein we could enact our citizenship.

\section{Cooking as intangible cultural heritage - Cooking as commoning}

Arguably, acts of commoning were implicit to the kitchen's ethos and practice. To speak about commoning rather than commons follows a current shift in the relevant theory, where authors such as Bollier and Helfrich $(2012 ; 2015)$ advocate the importance of recognising the processes of creating and nurturing community. This recognition is also a critique of the limited view of the commons as only a pool of resources (see Ostrom 2015). As Linebaugh puts it:

"To speak of the commons as if it were a natural resource is misleading at best and dangerous at worst. The commons is an activity and, if anything, it expresses relationships in society that are inseparable from relations to 
nature. It might be better to keep the word as a verb, an activity, rather than as a noun, a substantive" (Linebaugh 2008: 279).

Julie Ristau (2011), co-director of On the Commons, suggests:

"The act of commoning draws on a network of relationships made under the expectation that we will each take care of one another and with a shared understanding that some things belong to all of us-which is the essence of the commons itself. The practice of commoning demonstrates a shift in thinking from the prevailing ethic of "you're on your own" to "we're in this together" (On the Commons 2011).

Many of the practices, relationships and ethical considerations outlined in this quotation were indeed manifested in OneLoveKitchen. Nonetheless, when it comes to the spatial configuration of the OneLoveKitchen, we still need to refer to common space (which is definitely not just a pool of resources). Our kitchen was a common space: shared, porous, constantly in the making, redefined and never complete, collectively owned and relatively free from interference by external power structures (Stavrides 2016a).

"In common space, differences meet but are not allowed to fight for a potential predominance in the process of defining, giving identity to space. If common space is shared space, then its users-producers have to learn to give, not only take. Common space can thus essentially be described as "offered" space. Space offered and taken the way a present is. True, the offering and acceptance of a present can mediate power relations. But the commoning of space presupposes sharing as a condition of reciprocity" (An Architektur 2010: 23).

Further to this, in his recent monograph on 'common space' (2016b), Stavros Stavrides points out that:

"common space may be shaped through the practices of an emerging and not necessarily homogeneous community that does not simply try to secure its reproduction but also attempts to enrich its exchanges with other communities as well as those between its members. Common space may take the form of a meeting ground, an area in which 'expansive circuits of encounter' intersect" (Stavrides 2016b: 11).

OneLoveKitchen was precisely such an intersection in our 'expansive circuits of encounter', where we, (previously) strangers, took the opportunity to share a "common world-in-the-making". To realise forms of cooperation through sharing, commoning has to overspill any fixed community boundaries by always 
being open to 'newcomers', strangers (Rancière 2006: 42). As argued earlier, the topology most conducive to this act of commoning is that of a meshwork, rather than that that of the (bounded) community. Huron also makes this point quite explicitly:

"In order to change the balance of power in the contested urban environment, what is precisely needed is to create networks with people who were once strangers but could become allies, or even friends. This is the specific challenge of urban commons: to weave new networks of trust and care amid the alienating pressures of the capitalist cityscape" (Huron 2015: 14-15).

The strangers that make and sustain porous common spaces within the capitalist cityscape are (also) people on the move, nomad citizens: activists from Global North; migrants and refugees from Global South. Common spaces are often reclaimed and/or reconstituted at a point of crisis, when deep human bonds of caring and mutual aid (bonds that are often imperiled by, for instance, forced displacement, migration, precarious labour, class exploitation, gender and race discrimination) are (re-)forged between people who were up to that point strangers. So, through commoning, these otherwise strangers come together to negotiate co-governance and affective practices of caregiving and taking (see Kurtz 2001). Here, the commons are revalued as an economy of care, love and mutual aid (after Hardt 2007; Hardt and Negri 2009 Hardt, see also Kropotkin 1902).

As noted, commoning is never complete. It is perpetually in the making; its horizon is tenuous, ever-retreating. In this emerging commons, strangers look into the mist and strive to locate others, an unrealised potential for nonterritorially bound, porous and inclusive networks of comradeship built on the sharing and co-shaping of common values.

In OneLoveKitchen, our act of commoning extended beyond our kitchen and our cooking and eating together, to embrace and, by doing so reshape, a wider network of other spaces in Athens. Since we did not have a fixed venue to serve our food, we moved across the city like nomads, making use of spaces made available to us within Athens' wider solidarity network. In our peregrination, we weaved lines that linked together various spaces across the city into a mobile commons, or, rather, a nomadic, rhizomic commons in the making. It is important to clarify here that nomadic commons as a term is not a synonym to a frivolous, ephemeral space of flows (see Castells 2009). Nomadic space is still predicated upon relationships and trust. Along with the members of the OneLoveKitchen, there was an infrastructural network of helpers who worked with us during our pop-up events: from those who lent us kitchen equipment, a van to transport the food to the event venues, the catering/serving staff and the kitchen porters to the food suppliers, venue occupants and clients. The infrastructure of the OneLoveKitchen was based on relations and collective 
work: friends and comrades made our events happen by offering their skills and facilities, but most importantly their solidarity. Together with a network of spaces, we created an over-expanding community who was present, relevant and empowering.

The configuration of the rhizomic topology of our network of solidarity was ever-changing, contingent upon the emergence and disappearance of transient entry points i.e. new occupied spaces, members arriving and departing (see Deleuze \& Guattari 1987). The rhizomic topology and relational infrastructures of our African collective kitchen may offer another layer into the definition of ICH where the 'intangible' is connected to the affective and immaterial assets rather than what is produced within. Here, the relational is in sync to 'affective infrastructures' as defined by Lauren Berlant (2016) accommodating multiplicity and difference as much as allowing movement while recognizing collective affect inprinted on patterns, habits, norms within the common shared spaces. Speaking of movement and action (i.e. following Berlant's (2016: 399) argument that "the commons is an action concept that acknowledges a broken world"), affective infrastructures are discovered by looking at the making of cultural heritage by aterritorial communities. The latter implies those who are either displaced as refugees and/or intentionally (trans)located as for example activists and artists from the Global North. The cultural values produced within a collective project such as the OneLoveKitchen are relational and affective par excellence. Since there was no past history connecting its members and spaces (as most of us were newcomers in Athens, and knew each other for a short time), our sharing practices and common values of solidarity and care gave shape to our community in the here-and-now and strengthened relations between us and those we collaborated with throughout the five months of our kitchen's existence. It is, therefore, pertinent to redefine ICH in the context of displacement and mobile citizenship, to challenge notions of the 'cultural' as predicated (only) on borders, nation-states and localities. The OneLoveKitchen demonstrates how cultural value can be created and shared through an ever evolving and emerging heritage of commoning practices.

\section{Concluding remarks}

The nomadic, networked nature of OneLoveKitchen, an African collective kitchen in Athens, compels us to question the limitations of current understandings of cooking as intangible culture (and, I argue, intangible culture more generally). In times of increasing population mobility, migration and global nomadism, the concept of intangible cultural heritage needs to open up to include cultures produced by people on the move. Culinary culture, especially, cannot be seen as situated only at long-established, clearly demarcated communities at fixed geographical locations. By crossing and contesting borders, both geographical and cultural, and through enacting their nomad 
citizenship in networks of interaction, sharing, care and solidarity, migrants and refugees cross-pollinate culinary and political practices in their host countries. OneLoveKitchen, a common shared space co-created by migrants, refugees and other nomad citizens, exemplifies the practices of interchange whereby 'strangers' and 'newcomers' subvert current understandings of intangible cultural heritage as a prerogative of demarcated, spatially fixed communities. OneLoveKitchen, has enriched Athenian culinary culture with recipes and ingredients from Africa, and, also, with the practices of sharing, caring, solidarity and hospitality that emerged within it. These practices, shaped through the political actions of care and commoning, arguably constitute a distinctive kind of intangible cultural heritage: not fixed, but in perpetual flux; always in the making; socially and politically transformative.

\section{Acknowledgements}

Special thanks to the OneLoveKitchen members: Addis, Cheikh, Christos, David, Elisa, Esther, Jeff, Katlin, Lauren, Lauretta, Luisa, Mageb, Omar, Senait, Susan, Thanassis, Vicki.

\section{Bibliography}

Adapon, J. (2008). Culinary art and anthropology. Oxford, United Kingdom: Berg.

Agamben, G. (1998). Homo Sacer: Sovereign power and bare life. Redwood City, CA: Stanford University Press.

An Architektur. (2010). On the commons: A public interview with Massimo De Angelis and Stavros Stavrides. e-flux - Journal, 17 (June-August). Retrieved November 20, 2019, from https://www.e-flux.com/journal/17/67351 /on-the-commons-a-public-interview-with-massimo-de-angelis-and -stavros-stavrides/.

Appadurai, A. (1993). Patriotism and its futures. Public Culture, 5(3), 411-429. Arendt, H. (1958). The human condition. Chicago, IL: The University of Chicago Press.

Arendt, H. (1990). On revolution. London, United Kingdom: Penguin Books.

Art of Hosting. (n.d.). What is the art of hosting conversations that matter? Retrieved November 20, 2019, from http://www.artofhosting.org/what-is -aoh/.

Bassel, L. \& Emejulu, A. (2018). Minority women and austerity: Survival and resistance in France and Britain. Bristol, United Kingdom: Policy Press.

Berlant, L. (2016). The Commons: Infrastructures for Troubling Times*. Environment and Planning D: Society and Space, 34(3), 393-419. DOI: https://doi.org/10.1177/0263775816645989. 
Bollier, D. \& Helfrich, S. (Eds.). (2012). The wealth of the commons: A world beyond market and state. Amherst, MA: Levellers Press.

Bollier, D. and Helfrich, S. (Eds.). (2015). Patterns of commoning. Amherst, MA: The Commons Strategy Group \& Off the Commons Books.

Bouchenaki, M. (2003). The interdependency of the tangible and intangible cultural heritage. In 14th ICOMOS General Assembly and International Symposium: Place, memory, meaning: preserving intangible values in monuments and sites, 27-31 October 2003, Victoria Falls, Zimbabwe. Retrieved November 20, 2019, from http://openarchive.icomos.org/468/.

Brady, J. (2011). Cooking as inquiry: A method to stir up prevailing ways of knowing food, body, and identity. International Journal of Qualitative Methods, 10(4),321-34.DOI:https://doi.org/10.1177/160940691101000402.

Braidotti, R. (2011). Nomadic subjects: Embodiment and sexual difference in contemporary feminist theory. New York, NY: Columbia University Press.

Brulotte, R. L. and Di Giovine, M. A. (Eds.). (2016). Edible Identities: Food as Cultural Heritage. London: Routledge.

Castells, M. (2009). The rise of the network society, Vol. 1 ( $2^{\text {nd }}$ ed.). Malden, MA: Wiley-Blackwell.

Cirnu, C. E. (2015). The shifting paradigm: Learning to unlearn. Internet Learning, 4(1), 126-133.

Cohen, A. P. (1985). Symbolic construction of community. London, United Kingdom: Routledge.

Cornelli, E. M. (2012). A critical analysis of Nyerere's Ujamaa: An investigation of its foundations and values (Unpublished PhD Thesis). University of Birmingham, Birmingham.

Deleuze, G. \& Guattari, F. (1987). A thousand plateaus: Capitalism and schizophrenia. Minneapolis, MN: University of Minnesota Press.

Derrida, J. \& Dufourmantelle, A. (2000). Of hospitality. Stanford, CA: Stanford University Press.

Douzinas, C. (2013). Philosophy and resistance in the crisis: Greece and the future of Europe. Cambridge, United Kingdom: Polity.

Gañigueral, A. (2015). Can digital sharing economy platforms pull Latin America's informal sector into the mainstream? Yes. Americas Quarterly, Summer 2015 Issue: Trade is Back! Retrieved November 20, 2019, from https://www.americasquarterly.org/content/can-digital-sharing-economy -platforms-pull-latin-america $\%$ E2\%80\%99s-informal-sector-mainstream -yes.

Guimarães Jr., M. J. L. (2005). Doing anthropology in cyberspace: Fieldwork boundaries and social environments. In C. Hine (Ed.), Virtual methods: Issues in social research on the internet (pp. 141-156). Oxford, United Kingdom: Berg.

Hardt, M. (2007). About love. European Graduate School. Retrieved November 20, 2019, from: www.youtube.com/watch?v=ioopkoppabI. 
Hardt, M. \& Negri, A. (2009). Commonwealth. Cambridge, MA: Harvard University Press.

Hill Collins, P. (2000). Gender, black feminism, and black political economy. The Annals of the American Academy of Political and Social Science, 568(1), 41-53.

Holland, E. W. (2012). Global cosmopolitanism and nomad citizenship. In R. Braidotti, P. Hanafin \& B. Blaagaard (Eds.), After cosmopolitanism (pp. 149-165). Oxon, United Kingdom: Routledge.

Huron, A. (2015). Working with strangers in saturated space: Reclaiming and maintaining the urban commons. Antipode, 47(4), p. 963-979.

ICH-UNESCO. (2017). Art of Neapolitan 'Pizzaiuolo'. Retrieved November 20, 2019, from https://ich.unesco.org/en/RL/art-of-neapolitan-pizzaiuolo -00722 .

ICH-UNESCO. (n.d.). What is intangible cultural heritage? Retrieved November 20, 2019, from https://ich.unesco.org/en/what-is-intangible -heritage-00003.

ICOMOS. (2002). International Cultural Tourism Charter: Managing tourism at places of cultural and heritage significance. Retrieved November 20, 2019, from https://www.icomos.org/charters/tourism_e.pdf.

Ingold, T. (2010). Bringing things to life: Creative entanglements in a world of materials. Realities Working Paper, 15. Manchester, United Kingdom: University of Manchester. Retrieved November 20, 2019, from http:// hummedia.manchester.ac.uk/schools/soss/morgancentre/research /wps/15-2010-07-realities-bringing-things-to-life.pdf.

Knecht, U., Krueger, C., Markert, D., Moser, M., Mulder, A.-Cl., Praetorius, I., ... \& Trenkwalder-Egger, A. (2012). ABC des guten Lebens. Russelsheim am Main, Germany: Christel Goettert Verlag.

Kropotkin, P. (1902). Mutual Aid: A Factor of Evolution. New York: McClure Phillips \& Co.

Kurtz, H. (2001). Differentiating Multiple Meanings of Garden and Community. Urban Geography 22(7): 656-670. DOI: https://doi.org/10.2747/0272 -3638.22 .7 .656 .

Lassiter, L. E. (2005). The Chicago guide to collaborative ethnography. Chicago, IL: The University of Chicago Press.

Leach, J. (2003). Creative land: Place and procreation of the Rai Coast of Papua New Guinea. New York, NY: Berghahn Books.

Linebaugh, P. (2008). The Magna Carta Manifesto: Liberties and commons for all. Berkeley, CA: University of California Press.

Marcus, G. E. (1998). Ethnography through thick \& thin. Princeton, NJ: Princeton University Press.

Mauss, M. (1990). The gift: The form and reason for exchange in archaic societies ( $2^{\text {nd }}$ ed.). London, United Kingdom: Routledge. 
Mitsopoulos, M. \& Pelagidis, T. (2011). Understanding the crisis in Greece: From boom to bust. London, United Kingdom: Palgrave Macmillan.

Mylonas, Y. (2014). Crisis, austerity and opposition in mainstream media discourses of Greece. Critical Discourse Studies, 11(3), 305-321.

Nyerere, J. K. (1968). Ujamaa: Essays on socialism. Dar-es-salaam, Tanzania: Oxford University Press.

Papadopoulos, D. \& Tsianos, V. S. (2013). After citizenship: Autonomy of migration, organisational ontology and mobile commons. Citizenship Studies, 17(2), 178-196.

Participatory Budgeting Project. (2012). Mission. Retrieved November 20, 2019, from https://www.participatorybudgeting.org/mission/.

Pleios, G. (2013). Ta MME a

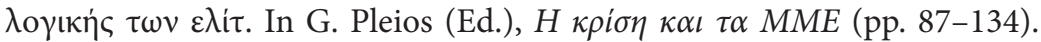
Athens, Greece: Papazisis.

Rancière, R. (2006). The politics of aesthetics. London, United Kingdom: Continuum.

Ristau, J. (2011, March 3). What is commoning, anyway?: Activating the power of social cooperation to get things done - and bring us together. On the Commons. Retrieved November 20, 2019, from http://www.onthecommons .org/work/what-commoning-anyway\#sthash.6oYDUwk8.dpbs.

Shutte, A. (1993). Philosophy for Africa. Rondebosch, South Africa: University of Cape Town Press.

Social Innovation Europe. (2016, January 26). Options Foodlab: How food making and sharing is supporting migrant integration in Greece. Retrieved November 20, 2019, from https://socialinnovationexchange.org/insights /options-foodlab-how-food-making-and-sharing-supporting-migrant -integration-greece.

Stavrides, S. (2016a). Common space: The city as commons. London, United Kingdom: Zed Books.

Stavrides, S. (2016b) Common space as threshold space: Urban commoning in struggles to re-appropriate public space. In Public-open spaces as common goods: A park for all at Hellinikon: File: Public event. Biennale Architectura 2016, 25 September 2016 (pp. 9-20). Retrieved November 20, 2019, from https://www.academia.edu/30344547/Public-open_spaces_as_common _goods._A_park_for_all_at_Hellinikon._File_of_public_event_2016_.

Symons, M. (1994). Simmel's gastronomic sociology: An overlooked essay. Food and Foodways, 5(4), 333-351. DOI: https://doi.org/10.1080/07409710 .1994.9962016.

Taylor, T. (2007). The commodification of music at the dawn of the era of 'Mechanical Music'. Ethnomusicology, 51(2), 281-305.

Travlou, P. (2013). Rhizomic ethnographies: Rhizomes, lines and nomads: Doing fieldwork with creative networked communities. In S. Biggs (Ed.), 
Remediating the social (pp. 65-69). Bergen, Norway: University of Bergen, ELMCIP.

Travlou, P. (2017). The making of OneLoveKitchen: Commoning the assembly. In J. Marketou \& S. Bailey (Eds.), Organizing from Below/HOW Assemblies Matter? (pp. 6-7). New York: Naked Punch Publications.

Tsilimpounidi, M. (2016). Sociology of crisis: Visualising urban austerity. London, United Kingdom: Routledge.

Vasiljević, J. (2016). The possibilities and constraints of engaging solidarity in citizenship. Filozofija I Društvo, 27(2), 373-386.

Wilson, D. (2017). Commoning in sonic ethnography (or, the sound of ethnography to come). Commoning Ethnography, 1(1), 125-136.

Wolff, K. H. (1950). The sociology of Georg Simmel. New York, NY: The Free Press. 